\title{
A FILOSOFIA NO CURRÍCULO E NA PERCEPÇÃO DE ALUNOS E PROFESSORES DO ENSINO MÉDIO BRASILEIRO E DO BACHILLERATO ESPANHOL: ESTUDO COMPARATIVO SOBRE O PAPEL DA FILOSOFIA E SUAS CONDIÇÕES DE ENSINO ${ }^{1}$
}

\author{
FILOSOFÍA EN EL CURRÍCULO Y EN LA PERCEPCIÓN DE LOS \\ ESTUDIANTES Y PROFESORES DE LA ESCUELA SECUNDARIA BRASILEÑA \\ Y DEL BACHILLERATO ESPAÑNOL: ESTUDIO COMPARATIVO SOBRE EL \\ ROL DE LA FILOSOFÍA Y SUS CONDICIONES DE ENSEÑANZA
}

THE PHILOSOPHY IN THE CURRICULUM AND IN THE PERCEPTION OF STUDENTS AND TEACHERS OF THE BRAZILIAN HIGH SCHOOL AND THE SPANISH BACHILLERATO: A COMPARATIVE STUDY ON THE ROLE OF PHILOSOPHY AND ITS CONDITIONS OF TEACHING

Maria Fernanda Alves GARCIA MONTERO²

RESUMO: O presente artigo tem como objetivo analisar comparativa e criticamente o ensino da Filosofia no Ensino Médio brasileiro e no Bachillerato espanhol, tanto no que tange ao seu lugar no currículo, quanto no que se refere às percepções de alunos e professores sobre seu ensino, tendo como pano de fundo as reformas educacionais implantadas nesses países após o processo de redemocratização. A coleta de dados, no âmbito do currículo prescrito, foi realizada por meio de análise de documentos pertinentes às reformas e ao ensino da Filosofia e de provas específicas que avaliam esse nível de ensino nos dois países. Os dados sobre o currículo em ação foram obtidos por meio de questionários aplicados a 31 alunos concluintes do Ensino Médio de uma escola pública da Cidade de São Paulo (Brasil), a 25 alunos concluintes do Bachillerato de uma escola pública da Cidade de Guadalajara (Espanha) e a 04 professores de Filosofia dessa etapa da escolaridade, dois brasileiros e dois espanhóis, todos profissionais de escolas públicas. Os dados referentes aos sujeitos espanhóis foram coletados com realização de Estágio de Doutorado no Exterior - PDSE (Programa de Doutorado Sanduíche no Exterior) - CAPES (Coordenação de Aperfeiçoamento de Pessoal de Ensino Superior).

PALAVRAS-CHAVE: Filosofia. Ensino médio. Bachillerato. Reforma educacional no Brasil e Espanha. Educação comparada.

${ }^{1}$ CNPq - Conselho Nacional de Desenvolvimento Científico e Tecnológico; CAPES - Coordenação de Aperfeiçoamento de Pessoal de Ensino Superior.

${ }^{2}$ Pontifícia Universidade Católica de São Paulo (PUCSP) - Brasil. Doutora em Educação, pelo PEPG em Educação: História, Política, Sociedade da PUC-SP. Vinculada ao grupo de pesquisa Docência em suas Múltiplas Dimensões. E-mail: fefamontero@gmail.com 
RESUMEN: Este artículo tiene como objeto analizar comparativa y críticamente la enseñanza de la filosofía en la escuela secundaria brasileña y en el Bachillerato español, en lo que se refiere a su lugar en el currículo, y en lo que se refiere a la percepción de los estudiantes y profesores acerca de su enseñanza, teniendo como plan de fondo las reformas educativas implementadas en esos países después del proceso de redemocratización. La recogida de datos dentro del currículo prescrito, se llevó a cabo mediante el análisis de los documentos relacionados con la reforma y la enseñanza de la filosofía y pruebas específicas que evalúan este nivel de la escolaridad en ambos países. Los datos sobre el currículo en acción fueron obtenidos a través de cuestionarios dados a 31 estudiantes que se gradúan de secundaria en una escuela pública en la ciudad de Sao Paulo (Brasil), a 25 estudiantes que se gradúan de bachillerato de un colegio público en la ciudad de Guadalajara (España ) y a 04 profesores de filosofía de esta etapa escolar, dos brasileños y dos españoles, todos profesionales de la escuela pública. Los datos de los sujetos españoles fueron recogidos a través de pesquisa en el exterior por medio de beca PDSE (Programa de Doutorado Sanduíche no Exterior/Programa de Doctorado Sandwich en el Exterior) - CAPES (Coordenação de Aperfeiçoamento de Pessoal de Ensino Superior /Coordinación de Perfeccionamiento de Personal para la Enseñanza Superior).

PALABRAS-CLAVE: Filosofía. Escuela secundaria. Bachillerato. Reforma de la educación en Brasil y España. Educación comparada.

ABSTRACT: The present article aims to analyze, comparative and critically, the teaching of Philosophy in Brazilian High School and in the Spanish Bachillerato, both in regard to its place in the curriculum, and in regard to the perceptions of students and teachers about its teaching, having as a background the educational reforms implemented in those countries after the redemocratization process. The research was conducted, in regard to the data collection, in the scope of the prescribed curriculum, through analysis of documents related to the reforms, to the teaching of philosophy and of specific tests that assess this level of education in both countries. The data on the curriculum in action were obtained through questionnaires given to 31 graduating high school students from a public school in the city of São Paulo (Brazil), 25 graduating students of Bachillerato of a public school in the city of Guadalajara (Spain) and 04 philosophy teachers of this school stage, two brazilians and two spanish, all professionals from public schools. The data related to the Spanish participants with the realization of a Doctoral internship abroad - PDSE (Programa de Doutorado Sanduiche no Exterior/ Doctoral Sandwich Abroad Program) - CAPES (Coordenação de Aperfeiçoamento de Pessoal de Ensino Superior/ Higher Education Personnel Improvement Coordination).

KEYWORDS: Philosophy. High school. Bachillerato. Educational reform in Brazil and Spain. Comparative education.

\section{Introdução}


O problema central deste trabalho consiste em analisar, comparativa e criticamente, a disciplina Filosofia no currículo e na percepção de alunos e professores do ensino médio brasileiro e do bachillerato espanhol, investigando o papel da Filosofia nesse nível de escolaridade e as condições de seu ensino nesses dois países. Trata-se de um estudo acerca das diretrizes oficiais para o ensino de Filosofia e também acerca de como essas diretrizes estão sendo traduzidas na prática, a partir da percepção de professores e alunos, no Brasil e na Espanha, identificando que relações se estabelecem, hoje, entre os âmbitos prescrito e interativo do currículo, já que, de acordo com Sacristán (2007), o currículo é um processo que se mostra na interação de todos os seus contextos, que vão desde o âmbito de decisões políticas e administrativas que resultam no currículo oficial (documentos curriculares) até sua transformação em currículo em ação. Sem conhecer as interações existentes entre esses dois âmbitos do currículo, não se pode compreender o que de fato acontece aos estudantes e o que estes aprendem. A proposta, então, é a de estudar como a atual estrutura dos dois sistemas educacionais nesse nível de escolaridade foi pensada/elaborada; como foi o desenrolar das duas reformas; quais são as diretrizes oficiais hoje para o ensino da Filosofia nos dois países; o que está acontecendo nas escolas de ensino médio com a disciplina Filosofia - o que está sendo ensinado e o que está sendo aprendido.

Assim sendo, analisar comparativamente o lugar da disciplina Filosofia no currículo do ensino médio e a realidade de seu ensino na percepção de alunos e professores nesses dois países interessa a esta pesquisa pelo que essa relação entre intenção e realidade pode revelar sobre o papel da Filosofia nesse nível de escolaridade e sobre as condições de seu ensino, bem como pelos elementos de compreensão que podem ser encontrados na comparação entre as duas realidades.

Considerou-se, nesta pesquisa, a existência de uma estreita relação entre Brasil e Espanha no que diz respeito às diretrizes curriculares atuais. A reforma educacional brasileira, em curso durante toda a década de 1990, encontrou na reforma educacional espanhola dos anos 1980 sua principal inspiração. Mas a conexão entre as reformas espanhola e brasileira vai além da simples inspiração. A conexão entre as duas se estreitou ainda mais quando o MEC contratou o ex-diretor da reforma espanhola, César Coll, da Universidade de Barcelona, como consultor para a elaboração dos Parâmetros Curriculares Nacionais (PCNs).

Logo nos primeiros debates sobre a reforma educacional brasileira, no começo dos anos 1990, ficou decidido que o modelo a ser seguido seria o implementado na 
Espanha sob a coordenação de César Coll. Das discussões no Ministério de Educação e Cultura (MEC), das quais Coll participou como assessor técnico, surgiram os PCNs (MOREIRA, 1997).

Por esse motivo discutir a reforma espanhola é particularmente importante para nós brasileiros, já que um dos principais responsáveis pela referida reforma participou como consultor internacional para a reforma brasileira. Dessa forma, muitas de suas ideias passaram a influenciar todo o nosso sistema de ensino. Mas, além da forte influência das propostas educacionais espanholas, outro motivo nos leva a escolher a Espanha para um estudo comparado com o Brasil: a Espanha é um país que pertencia à "periferia" da União Europeia, à qual só se juntou em 1986. Desde então vem se empenhando para inserir- se efetivamente na economia europeia e mundial. Dentro desse contexto, a educação tornou-se eixo fundamental. Situação semelhante acontece com o Brasil, país ainda periférico no capitalismo mundial, que tem realizado esforços para inserir-se na economia global (SENE, 2009).

Os dois países passaram por longos períodos de exceção. Lá, a ditadura de Francisco Franco (1939-1975), e aqui, a ditadura militar (1964-1985). A promulgação de uma nova constituição, em 1978 na Espanha e em 1988 no Brasil, foi um divisor de águas para a abertura política e para a redemocratização dos dois países. Por esse motivo consideraremos aqui as leis educacionais do período pós-abertura política de cada um dos dois países.

No contexto dessas reformas educacionais, o Ensino Médio brasileiro e o seu correspondente espanhol, o Bachillerato, foram as etapas de ensino que mais sofreram alterações, que mais tiveram mudanças em suas estruturas. Em ambos os casos, se trata do nível de ensino que mais passou por mudanças, ora privilegiando a formação profissional, ora pondo em destaque a formação geral do indivíduo. Por esse motivo, e pelo fato da Filosofia ser disciplina obrigatória ${ }^{3}$ nesse momento da escolaridade, optouse por estudar esse nível de ensino. Assim, é no contexto dessas reformas pós-abertura política que os atuais sistemas de ensino da Espanha e do Brasil se constituíram e é dentro desses sistemas de ensino que a Filosofia se insere como disciplina obrigatória. Por esse motivo se torna importante estudar a ambos.

${ }^{3}$ Quando da realização desta pesquisa, a Filosofia (e a Sociologia) ainda constavam como disciplinas obrigatórias no Ensino Médio (Lei n.ำ11684, de 2008). A medida provisória nº 746/2016 ainda não havia sido instaurada. 
Optou-se, então, por estudar, comparativamente, a disciplina Filosofia no currículo do Ensino Médio brasileiro e do Bachillerato espanhol, no contexto das reformas educacionais implementadas nos dois países após a abertura política, com o intuito de melhor apreender os fatos educativos e a existência de problemáticas educativas comuns aos dois países, bem como investigando percepções de professores e alunos, no Brasil e na Espanha, sobre o trabalho com essa disciplina e identificando relações que se estabelecem, hoje, entre os âmbitos prescrito e interativo do currículo.

Ruth Sautu (2005) afirma que a redação do marco teórico de um projeto de pesquisa deve incluir uma teoria geral e teorias substantivas. De acordo com a autora (2005), a teoria geral é aquela que, como já indica o nome, tem uma abrangência maior, engloba processos mais amplos. Já as teorias substantivas são aquelas que serão aplicadas ao problema específico estudado, são aquelas mais pontuais e "estreitas". Assim sendo, o marco teórico deste projeto inclui, como teoria geral, a Abordagem do Ciclo de Políticas, formulada por Ball e Bowe e como marco teórico substantivo, os conceitos de Currículo Oficial ou Prescrito e Regulamentado e Currículo em Ação, elaborados por Gimeno Sacristán e também os conceitos de Currículo e Disciplina, elaborados por Goodson e Chervel, além do conceito de Reforma de Viñao Frago.

A hipótese central que guia a pesquisa aqui apresentada é a de que a Filosofia, para além dos aspectos positivos da sua presença no currículo tornou-se trabalho sem sentido (alienado), tanto para alunos quanto para professores. Parte-se, então, da suposição de que existe uma sensível distância entre a natureza dos conteúdos da disciplina, os objetivos visados pelo professorado e as motivações do alunado, distância essa na qual interferem, de forma decisiva, as tensões e conflitos entre as intenções expressas nos textos oficiais, as percepções destes por parte de alunos e professores, os mecanismos oficiais de controle, as atividades e relações entre professores e alunos, seus pares e superiores.

\section{Objetivos}

Geral: Analisar comparativamente, o ensino da disciplina Filosofia no currículo do ensino médio brasileiro e do bachillerato espanhol no contexto das reformas educacionais implementadas nos dois países após a abertura política, discutindo tais reformas em sua modalidade estrutural - centrada no Ensino Médio - e curricular - 
focada na disciplina de Filosofia, bem como investigando percepções de professores e alunos, no Brasil e na Espanha, sobre o trabalho com essa disciplina.

Específicos: 1) Analisar a produção dos textos oficiais, diretrizes e objetivos expressos nas propostas para a disciplina de Filosofia nesse nível de ensino, nos dois países, identificando seus efeitos e a forma como são percebidos e implementados no contexto da prática; 2) Analisar, comparativamente, com base nas percepções de alunos concluintes e professores, como se dá o ensino da Filosofia nesse nível de ensino, no Brasil e na Espanha; 3) Estudar as duas reformas comparativamente, com o intuito de melhor apreender seus contextos e a existência de problemáticas educativas comuns ao Brasil e à Espanha.

\section{Procedimentos metodológicos}

a) Leitura e análise da legislação e seus analistas:

Estudo do desenvolvimento dos dois processos de reforma em questão a partir da análise de documentos oficiais, da leitura de César Coll (principal inspirador das duas reformas em questão) e da leitura de autores que analisam e discutem as

b) Leitura e análise dos documentos referentes à Filosofia nos currículos de ensino médio no Brasil e no Bachillerato na Espanha e seus analistas:

Breve estudo histórico do percurso da Filosofia como disciplina nos dois países, a fim de investigar como a Filosofia aparece no sistema educacional dos dois países e quais são os parâmetros e diretrizes propostas para essa disciplina pelos documentos oficiais.

c) Análise da percepção de alunos e professores sobre as aulas de Filosofia hoje por meio de questionários:

O estudo da percepção de alunos e professores sobre as aulas de Filosofia se mostra necessário nessa pesquisa, especialmente se considerarmos as afirmações de Gimeno Sacristán (1998) e Goodson (2001 e 2012) de que as propostas oficiais são sempre transformadas quando postas em prática. 
d) Análise das provas ENEM (Brasil) e PAU (Espanha):

Para complementar o estudo sobre as realidades nas escolas optou-se também por analisar as questões do ENEM - Exame Nacional do Ensino Médio, no Brasil, e da PAU - Prueba de Acceso a la Universidad, na Espanha, a fim de determinar a natureza das questões e conteúdos presentes nas duas provas. Tal estudo se mostrou necessário, pois, ao final desse nível de ensino, os alunos são avaliados e tais avaliações são organizadas de acordo com os objetivos determinados por lei, para verificar se os egressos atingiram aquilo que era deles esperado. Os documentos oficiais são inspiradores de projetos pedagógicos e, consequentemente, da avaliação destes.

e) Análise comparativa dos dados coletados

Análise comparativa dos dados obtidos em cada uma das fontes investigadas, apresentando-os em quadros-síntese, gráficos, figuras e/ou tabelas, se e quando isso for necessário para compreensão dos aspectos sob análise.

Trata-se de pesquisa de educação comparada, definida por Sérgio Schneider e Cláudia Job Schmitt (1998) como o ato de confrontar duas realidades a fim não só de identificar semelhanças e diferenças, mas permitir nova compreensão do fenômeno em estudo. Trata-se de pesquisa que pode ser realizada com base em estudo bibliográfico e/ou em pesquisa de campo. Segundo os autores é a comparação que nos permite “(...) romper com a singularidade dos eventos, formulando leis capazes de explicar o social”. Nesse sentido, a comparação aparece como sendo inerente a qualquer pesquisa no campo das Ciências Sociais, esteja ela direcionada para a compreensão de um evento singular ou voltada para o estudo de uma série de casos previamente escolhidos (Schneider; Schmitt, 1998, p.49).

\section{Discussão e resultados}

As reformas no Brasil e na Espanha: apontamentos com destaque para o Ensino Médio e para o Bachillerato 
De acordo com Frigotto e Ciavatta (2011), qualquer objeto de análise dentro do campo das ciências humanas, que se queira tratar no âmbito das contradições, mediações e determinações que o constituem, implica, necessariamente, tomá-lo dentro da relação entre os planos estrutural e conjuntural. Implica, também, segundo os autores, em tomar o objeto não como um fato isolado ou como mera soma de fatores, mas sim tomá-lo por meio das mediações que o constituíram/constituem como parte de uma complexa totalidade histórica. Assim, é preciso levar em consideração a estruturação do cenário educacional dos atuais contextos sociais brasileiro e espanhol, se o que se pretende é entender a atual função do Ensino Médio e do Bachillerato e, dentro deles, entender a situação da Filosofia.

No Brasil, embora a abertura política seja "localizada" em 1985, foi somente com a aprovação da nova Constituição, em 1988, que a transição do período ditatorial para a democracia efetivamente se consolidou. A nova lei máxima tornou-se, então, referência para a elaboração da Lei de Diretrizes e Bases (LDB) de 1996, a qual foi aprovada no governo de Fernando Henrique Cardoso, em 20 de dezembro, e teve um processo lento e tumultuado de tramitação no Congresso, tendo sido aprovada oito anos depois da apresentação do primeiro projeto à Câmara dos Deputados ${ }^{4}$.

A reforma de 1990 no Brasil, que culminou na LDB/1996, propôs uma nova estrutura curricular, não mais baseada em conteúdos e disciplinas, mas baseada no desenvolvimento de habilidades e competências básicas, com ênfase em uma metodologia que privilegia o protagonismo do aluno, a integração entre as disciplinas e a contextualização dos conteúdos disciplinares, priorizando uma formação geral e polivalente, capaz de fomentar a aquisição de "competências gerais e transferíveis". Vimos também que a LDB de 1996 foi uma "guinada neoconservadora" em educação no Brasil, tendo sido desenvolvida dentro dos moldes do ideário neoliberal.

$\mathrm{Na}$ Espanha vimos que ocorreram muito mais reformas educacionais do que no Brasil, onde continua em vigor a LDB de 1996 (muito embora seu texto original já tenha sido alterado diversas vezes). Desde 1970, ano em que entrou em vigor a Ley General de Educación (LGE), sucederam-se 07 leis educacionais, sendo que a última, a LOMCE, foi aprovada no final de 2013 e é a primeira lei do PP (Partido Popular) relativa ao âmbito educacional a ser aprovada. Vimos que essa sucessão de leis é resultado do forte bipartidarismo que impera na Espanha. O enfrentamento entre PSOE

${ }^{4}$ Para maiores esclarecimentos ver: SAVIANI, Dermeval. A nova lei da educação: LDB, trajetória, limites e perspectivas. 8.ed.rev..Campinas/SP: Autores Associados, 2003. 238p. 
(Partido Socialista Obrero Español) e PP acaba gerando uma instabilidade e descontinuidade das políticas educacionais: o que um fazia em seu mandato o outro logo desfazia assim que chegava ao poder.

No entanto, segundo Benítez (2008) somente 03 dessas leis podem ser consideradas como verdadeiramente vertebradoras da educação espanhola: a) a LGE (1970), aprovada ainda durante o regime franquista, que tentou modernizar a estrutura do sistema educativo (que era regido pela Ley Moyano desde 1857) para adequá-lo a uma sociedade imersa em um intenso processo de mudanças e que determinou a estrutura básica do sistema educativo até os anos 1990; b) a LOGSE (Ley de Ordenación General del Sistema Educativo), de 1990, que revogou e substituiu a LGE e promoveu avanços estruturais importantes, como a extensão da escolaridade obrigatória e gratuita até os 16 anos e cuja estrutura institucional, apesar das diversas mudanças introduzidas nos anos que se seguiram, permanece; e c) a LOE (Ley Orgánica de Educación), de 2006, que transformou a disciplina de religião em disciplina optativa para os alunos (a oferta dessa disciplina era, até então, obrigatória para as escolas), incluiu uma nova disciplina obrigatória: Educación para la Ciudadanía y los Derechos Humanos e buscou uma estabilidade do sistema educativo e o alcance da máxima qualidade da educação com a maior equidade social possível.

A LOMCE (2013), na Espanha também foi uma guinada neoconservadora, e se justifica afirmando a necessidade de formar indivíduos para uma nova sociedade, mais aberta, global e participativa, que exigiria novos perfis de cidadãos e de trabalhadores. Com uma forte orientação neoliberal, a LOMCE reorienta enfaticamente os objetivos da educação para colocá-los em coerência com as normas do mercado neoliberal, assumindo como prioridade da educação a promoção da competitividade econômica e do nível de prosperidade do país. Claro que, considerando que o objetivo é reorientar a educação para colocá-la em sintonia com as normas do mercado neoliberal, dizer que se visa a "prosperidade do país" não passa de um discurso falacioso, já que o que se pretende, de fato, é a prosperidade do capital.

No decorrer da análise das duas reformas em questão viu-se, também, que ambas estão fortemente atreladas a uma concepção construtivista da aprendizagem, concepção esta que pertence ao conjunto das linhas pedagógicas do "aprender a aprender", que têm, dentre suas características, a produção da adaptação dinâmica (Duarte, 2004), e isso significa "[...] produzir indivíduos com alta capacidade adaptativa às demandas da sociedade, elas estão, de fato, pretendendo produzir indivíduos que aceitem o sistema 
capitalista como única forma possível de sociedade" (Duarte, 2004, p.64). Ou seja, quando nos documentos oficiais se fala em "conhecer a realidade" o que se pretende na verdade é que se conheça a realidade não para fazer a crítica a essa realidade e construir uma educação comprometida com lutas por uma transformação social radical, mas sim para saber melhor quais competências a realidade social está exigindo dos indivíduos.

Assim, apesar das muitas diferenças que foram observadas, o que há em comum nas reformas educacionais elaboradas no Brasil e na Espanha depois dos respectivos processos de abertura política, é que a intenção que move ambas as reformas é o controle, a organização curricular calcada no discurso do ensino eficaz, de resultados, e não na formação dos sujeitos.

\section{A Filosofia como disciplina obrigatória no Ensino Médio Brasileiro e no Bachillerato espanhol}

A respeitos das orientações oficiais/legais específicas para a disciplina de Filosofia, dentro do Ensino Médio brasileiro e do Bachillerato espanhol, foram analisados, no Brasil: os Parâmetros Curriculares Nacionais (PCN); os PCN+ (Orientações Educacionais Complementares aos PCN); e as Orientações Curriculares Nacionais para o Ensino Médio (OCNEM), datados respectivamente de 2000, 2002 e 2006; e na Espanha, o Real Decreto n. 1467 de 2007, que define a estrutura e as enseñanzas mínimas do Bachillerato, que é uma lei complementar que regula a modalidade curricular no país. Esses documentos constituem uma reiteração das diretrizes e finalidades do Ensino Médio e do Bachillerato expressas nas leis gerais que regulam a educação nos dois países. O Real Decreto espanhol, ao contrario dos documentos brasileiros que representam apenas modelos e sugestões que podem ou não ser seguidos, tem caráter de lei. Vimos aqui que a Filosofia, até a LOE/2006, tem uma presença maior no Bachillerato espanhol, onde aparece como disciplina obrigatória nos dois anos do curso (Filosofia e Cidadania obrigatória para o primeiro ano e a de História da Filosofia obrigatória no segundo ano) do que no Ensino Médio brasileiro, onde, de acordo com a Resolução $n^{\circ}$, de 15 de maio de 2009, a Filosofia (e a Sociologia) devem ser obrigatórias em, pelo menos, um dos anos do Ensino Médio. No entanto, com a aprovação da LOMCE/2013, há uma redução considerável da carga horária da Filosofia dentro do Bachillerato. A disciplina passa a ser obrigatória somente para $01^{\circ}$ 
ano e passa a ser optativa para o $2^{\circ}$ ano (as alterações para o $1^{\circ}$ ano foram introduzidas no ano letivo 2015/2016; já as alterações para o $2^{\circ}$ ano foram programadas para o ano letivo 2016/2017).

No caso brasileiro, apesar de algumas contradições, se considerarmos os princípios gerais do Ensino Médio, definidos na LDB/96 e reforçados nas DCNEM (Parecer CNE/CEB n 15/98), o espírito da proposta de ensino desenvolvida nesses nos PCNs, nos PCN+, e nas OCNEM, é bem coerente com a concepção delineada nos textos que compõem as bases legais da educação brasileira. Além disso, a análise desses 03 documentos também permitiu ver certa evolução da importância dada à presença da Filosofia no currículo do Ensino Médio, uma vez que no primeiro documento (PCN, de 2000) tem-se uma defesa da transversalidade da Filosofia enquanto que no último (OCNEM, de 2006) tem-se uma defesa de um espaço próprio e obrigatório para a Filosofia.

No Real Decreto espanhol há também uma tendência a considerar a transversalidade como uma das principais características da Filosofia mas, embora haja o discurso da transversalidade e da interdisciplinaridade, o Real Decreto apresenta uma parte especifica para a determinação dos conteúdos e conhecimentos próprios da Filosofia que devem ser tratados em cada uma das duas disciplinas filosóficas lecionadas para o Bachillerato (Filosofia e Cidadania, História da Filosofia) dando um foco um pouco mais acentuado a esses conteúdos e conhecimentos, não lhes atribuindo apenas um papel secundário, como se fossem apenas o meio para desenvolver habilidades e competências ditas filosóficas. Mas o ponto que todos os documentos analisados têm em comum, é o fato de todos considerarem a reflexão como sendo a principal especificidade da Filosofia.

\section{As provas: ENEM e PAU}

Já na análise das duas avaliações externas, os dados revelaram que, na prova do ENEM analisada (prova rosa/2013) ${ }^{5}$, o conteúdo de Filosofia teve, no mínimo, o mesmo peso que o conteúdo de outras disciplinas das Ciências Humanas - a Geografia e a

${ }^{5}$ Para evitar fraudes (colas indevidas) a prova do Enem é realizada em 4 versões de cores diferentes, são elas: amarela, azul, branca e rosa. Apesar das cores diferentes, as provas possuem as mesmas questões, pois o que difere uma da outra é a ordem em que as questões são montadas. 
História - apesar da Filosofia ter uma carga horária bem inferior à carga dessas disciplinas. Isso significa, aparentemente, que a Filosofia deixou de ser encarada e abordada como conteúdo meramente interdisciplinar, presente apenas em questões específicas de outras disciplinas. No entanto, a maioria das questões especificas de Filosofia nessa prova brasileira, não exige que o aluno tenha domínio de conhecimentos de Filosofia, já que, pelo teor das perguntas, para respondê-las, basta, apenas, que se saiba ler e interpretar. Além disso, o modelo adotado pelo ENEM, de questões de múltipla escolha, representa um modelo simplista de avaliação.

Como as respostas simples só são possíveis a perguntas simples, a avaliação à base de exames com perguntas precisas, ou de provas objetivas, apela para processos intelectuais pouco complexos nos alunos/as, exige a rememoração de informações mais do que elaborações pessoais e cognitivas complexas, anulando a expressão pessoal do aluno (GIMENO SACRISTÁN, 2007, p. 308).

No que diz respeito à Espanha, constatou-se que o sistema de seleção para as universidades espanholas apresenta uma dinâmica inteiramente diferente do brasileiro. As questões da PAU da Comunidade de Madrid, analisadas neste trabalho, oriundas da prova de Historia da Filosofia (convocatórias de setembro para o ano letivo 2013-2014), mostraram que existe uma necessidade de que o curso de Filosofia no Bachillerato abarque, de forma minimamente aprofundada, um número maior de conteúdos, pois são questões dissertativas que exigem que o aluno tenha uma formação filosófica relativamente sólida, pois são consideravelmente densas; ou seja, para respondê-las é preciso mais do que a capacidade de ler e interpretar textos.

A análise dessas provas deixou clara a influência que avaliações externas como o ENEM e a PAU exercem sobre o currículo interativo. Tais avaliações são organizadas de acordo com os objetivos determinados nas grandes leis organizadoras da educação, a LDB/1996 e as DCNEM no Brasil e a LOE/2006 e a LOMCE/2013 na Espanha.

Essa influência fica especificamente clara em declarações como as da Profa. D da Espanha, quando ela afirma que "[...] con la LOMCE en 1 de Bachillerato se dispone de menos autonomía pues la ley marca los autores o la forma de trabajar algunos estándares. El 2 de Bachillerato es marcado por la $P A U^{\prime \prime}$ e que uma das principais finalidades do Bachillerato é "[...] sobretodo preparación para superar la PAU. El 2 de Bachillerato esta directamente enfocada a esas pruebas de acceso a la universidad." As falas dessa professora espanhola confirmam as afirmações de Gimeno Sacristán (2007) 
quando ele diz que a avaliação externa é sim, uma forma de controle sobre o currículo; o que se faz com o exame externo, segundo esse autor, "[...] é obrigar ao cumprimento do currículo estabelecido, que de outra forma ficaria sempre a mercê das interpretações do professor/a" (p.320).

\section{Os sujeitos: professores e alunos}

Os dados coletados com os professores de Filosofia, atuantes em escolas publicas do Brasil e da Espanha, revelam um quadro nada otimista. O que se percebe é que esses professores, muito embora se declarem críticos a respeito da atual organização do sistema e bem cientes das limitações e dos problemas dessa organização, não parecem estar conseguindo quebrar as barreiras externas impostas à sua pratica; eles não parecem estar conseguindo superar as interferências oficiais. O que nos leva em direção a essa conclusão é o fato de todos, indistintamente, afirmarem que utilizam de alguma maneira as propostas oficiais como guia para sua prática. O caso mais revelador desse aspecto é o da Profa. D, que cita com veemência a força de imposição e cerceamento da autonomia docente exercida pela LOMCE. A própria professora destaca em seu depoimento que a LOMCE, para além de definir os temas, autores e conteúdos que devem ser tratados, também define a forma de trabalhá-los. Esse cerceamento fica ainda mais claro quando se pensa que a PAU, cuja superação é o principal objetivo dos alunos do Bachillerato, é baseada nesses conteúdos e, portanto, se torna mais uma ferramenta poderosa de impedimento à autonomia docente.

No que diz respeito à coleta de dados com os alunos, cabe aqui uma justificativa a respeito da diferença de contexto dos alunos: São Paulo (cidade grande, capital) X Guadalajara (cidade pequena, interior). O plano inicial era coletar dados com alunos residentes na cidade de Madrid, outra cidade grande e também capital. No entanto, uma mudança nesse quadro inicial tornou-se necessária. Para a realização do período de estágio no exterior com a bolsa sanduiche, não encontramos co-orientadores disponíveis dentro da área de ensino da Filosofia para jovens nas universidades de Madrid. Assim que, correndo o risco de ficar com essa parte da pesquisa comprometida e, tendo como oportunidade um professor da Universidade de Alcalá (Campus Guadalajara) disposto a orientar a pesquisa, tivemos que optar pela coleta de dados nessa cidade, caso contrario não teríamos dados referentes aos alunos espanhóis e a pesquisa talvez ficasse 
restrita a uma pesquisa das legislações brasileiras e espanholas, sem os sujeitos. Levando-se em consideração, então, essa diferença de contexto entre os alunos, fez-se o possível para que as demais caracterizações da pesquisa na Espanha fossem o mais parecidas possíveis com as da pesquisa realizada no Brasil. Assim, buscou-se aplicar o questionários a alunos brasileiros e espanhóis, que pertencessem a escolas que tivessem características e condições semelhantes.

$\mathrm{Na}$ análise dos dados, o que de fato chamou mais a atenção, foi uma contradição no seu posicionamento acerca da importância de se ensinar Filosofia. Ao mesmo tempo em que existe uma maioria de alunos, tanto no Brasil quanto na Espanha, que afirma ter interesse e gostar da disciplina, e também uma maioria que afirma que considera sim, o ensino da Filosofia importante, existe também uma maioria que opta pela diminuição da carga horária da Filosofia (!) e as razões mais citadas, tanto pelos alunos brasileiros quanto pelos espanhóis, são: a de que "Não são aulas importantes, não têm aplicação, não serão usadas na vida" e a de "Falta de interesse pessoal, não entende, tem dificuldade". Essa contradição vai se tornando ainda mais surpreendente quando se constata que a quantidade de alunos que consideram importante estudar Filosofia é ainda maior do que a de alunos que gostam/têm interesse pela Filosofia. Então, ao mesmo tempo em que a Filosofia é uma das mais citadas para ter sua carga diminuída, com razões que alegam falta de interesse, falta de importância, etc., ela também é tida como interessante e importante pela maioria dos alunos.

No entanto, com o desenvolver das análises do restante dos dados coletados com os alunos, chegou-se à conclusão de que essa dita contradição no posicionamento do alunos não seria, de fato, uma contradição. A nosso ver, os alunos conseguem avaliar que o que se espera deles, de fato, não é que eles se tornem aquele sujeito ideal, quase platônico, mas sim que eles sejam empregáveis e bem preparados para acompanhar a sociedade em acelerado processo de mudança. Dessa forma o fato de os alunos afirmarem que a Filosofia é importante, mas ao mesmo tempo a colocarem dentre as principais disciplinas das quais diminuiriam a carga horária, não seria, então, uma contradição. Este parece ser o drama da Filosofia: por uma lado cativa e excita a quem com ela interage, mas por outro lado, tem socialmente cerceado seu potencial de expansão.

Outra evidência que nos direcionou às conclusões apresentadas acima, é o fato de, quando perguntados a respeito do que eles consideram mais importante dentre tudo o que eles aprenderam na escola, os alunos (espanhóis e brasileiros) citarem, 
principalmente aprendizagens relacionais, afetivas, pessoais, com conotação ética e moral. Isso demonstra que são essas as aprendizagens mais significativas para eles. Assim, para a maioria dos alunos participantes desta pesquisa, a relação com a escola não implica uma relação com o saber. Para eles não se trata de ir à escola para obter uma formação, para obter conhecimentos, mas sim para obter meios de garantir sua inserção socioprofissional no mundo real. Para esses alunos, aprender é se tornar capaz de se adaptar às situações, de estar em conformidade com o que deles se exige, de operacionalizar isso da melhor maneira possível.

\title{
Considerações finais
}

O que se constata, então, é que a hipótese cunhada no inicio dessa pesquisa se confirma. A Filosofia, institucionalizada, está sujeita aos dispositivos e discursos legais e ao controle social que exercem, na medida em que a escola e seu currículo constituem instâncias que preparam para a vida e para a inserção dos sujeitos no mundo, ou seja, a escola veicula um conhecimento já solidificado e útil para a manutenção da sociedade.

Como vimos na análise das legislações educacionais do Brasil e da Espanha, existe nas orientações legais que regem o sistema educacional dos dois países uma categoria de magnitude indiscutível e absoluta, que seria o mercado. Este seria o responsável por orientar e delimitar a sociabilidade humana desejável. Desse modo, a formação humana deve, necessariamente, subordinar-se aos ditames das necessidades do mercado. Pode-se apreender que há claramente, então, uma subordinação do humano/social a um determinado tipo de organização produtiva que, entretanto, resta indiscutida porque indiscutível:

\begin{abstract}
A relação de determinação sociedade-cultura-currículo-prática explica que a atualidade do currículo se veja estimulada nos momentos de mudanças nos sistemas educativos, como reflexo da pressão que a instituição escolar sofre desde diversas frentes, para que adapte seus conteúdos à própria evolução cultural e econômica da sociedade (...) Isso confirma o ato de que, em nossa tradição e no campo jurídico administrativo, as reformas curriculares vão ligadas na estrutura do sistema mais que a um debate permanente sobre as necessidade do sistema educativo (GIMENO SACRISTÁN, 1998, p.20)
\end{abstract}

Nesse contexto, então, a escola não consegue se desvencilhar da condição de produzir trabalho alienado, tanto dos professores como dos alunos, e a função da 
Filosofia no currículo escolar se torna apenas a de ser mais um elemento concorrente para o atingimento da satisfação das necessidades do mercado. Esse predomínio quase que sem mediações do mercado, que também é conhecido por sociedade neoliberal, acaba, portanto, por determinar, mesmo que de formas indiretas, a função do ensino da Filosofia.

Na verdade, o que acontece é que a Filosofia não é uma disciplina que vai simplesmente ser deixada de lado por não servir. Ela é uma disciplina que, a partir do momento que se insere nessa organização escolar, visa justamente a manutenção do todo. Então não é o caso de que as aulas estejam sendo de fato formativas mas, por terem um conteúdo "não prático", é deixada de lado pelos alunos. As aulas não estão sendo formativas (no sentido adorniano da palavra) ${ }^{6}$ e da forma como estão sendo desenvolvidas servem sim, para essa conformação da vida dos alunos, justamente por estarem contribuindo para o desenvolvimento, nos sujeitos, de uma noção de reflexão como mera discussão e "opinismo", mas não, de fato, filosófica7; para um aceitar dogmático e acrítico: o "conhecer a realidade" e "refletir sobre", não num sentido de ser crítico a respeito daquilo que defendemos ou não, mas sim no sentido de conhecer bem as condições às quais temos que nos adaptar, "aprender a aprender" para poder acompanhar as rápidas mudanças do mundo moderno da produção. Então, a tarefa da Filosofia dentro dos currículos, nesse contexto mercadológico, seria a de formar indivíduos que refletem não para questionar, mas para se adaptar melhor. Sob a faceta de uma disciplina que não se encaixa comodamente na vida dinâmica do capitalismo, está uma matéria que na verdade serve para isso, para a manutenção do status quo.

Dessa forma, se torna difícil vislumbrar como o sistema educacional, da forma como está organizado na Espanha e no Brasil, possa contribuir para uma formação que colabore para a ampliação dos horizontes dos indivíduos, para a emergência de sujeitos conscientes de suas potencialidades e artífices da própria história; que contribua para a emancipação enquanto possibilidade de sair do estado de menoridade a que o ser humano está submetido na sociedade moderna (Adorno, 1979). Não se veem muitas

${ }^{6}$ Formação, segundo Adorno (1979), seria a apropriação subjetiva da cultura, de forma a contribuir para a ampliação dos horizontes dos indivíduos, para a emergência de sujeitos conscientes de suas potencialidades e artífices da própria história. A formação está inserida no próprio desenvolvimento histórico do ser humano, não apenas como reflexo das condições existentes, mas também como possibilidade de transformação destas.

7 De acordo com Saviani (1980) para que uma reflexão (que o autor caracteriza como sendo um pensamento consciente de si próprio) possa, de fato, ser adjetivada como filosófica, é preciso é preciso que ela satisfaça uma série de exigências, que seriam: a radicalidade, o rigor e a globalidade. Ou seja, é preciso que ela seja radical, rigorosa e de conjunto. 
possibilidades de as reformas aqui analisadas contribuírem para isso já que, dentro da atual organização dos dois sistemas educacionais, a escola não consegue se desvencilhar da característica de instância de produção de trabalho alienado, desprovido de sentido, tanto para os professores como para os alunos, mas carregado de sentido do ponto de vista da sociedade humana empolgada pelo capital.

É, principalmente, em decorrência dessa conjuntura que surgem os problemas internos da Filosofia enquanto disciplina escolar, tais como a dificuldade de se estabelecer objetivos que sejam próprios da Filosofia e de se definir qual a sua especificidade. E esses problemas, além de dificultarem ainda mais a autoafirmação da Filosofia como disciplina necessária à formação dos sujeitos, acabam contribuindo também para o acirramento das influências externas neoliberais.

Finalmente permito-me destacar aqui Inês Dussel (2009), a respeito da crise da transmissão escolar: "o que foi feito do ideal de transmitir a cultura a todos os cidadãos através da escola?" Para essa autora, o cerco à transmissão cultural está ligado ao declínio das humanidades na sociedade, na escola e, sobretudo, ao fato de que os elementos culturais que nos definem hoje, definem nossa vida e se tornam nossas referências passam a ser fornecidos, cada vez mais, pela televisão, pela internet, pela economia de mercado sem mediações. As humanidades estão, de fato, sitiadas...

\section{REFERÊNCIAS}

ADORNO, Theodor. Teoria de la seudocultura. In: HORKHEIMER, Max; ADORNO, Theodor. Sociologia. 3.ed. Madrid: Taurus Ediciones, 1979. p.175-199.

BENÍTEZ, Manuel de Puelles. Las grandes leyes educativas de los últimos doscientos años. Participación Educativa, n.7, p.7-15, 2008. Disponível em: <https://dialnet.unirioja.es/servlet/articulo?codigo=3105108>. Acesso em: 10 dez. 2015

DUARTE, Newton. Educar para o capitalismo. Entrevista concedida à jornalista. Verônica Bercht. Revista Reportagem, Araraquara, ano V, n. 52, p.63-66, janeiro de 2004.

DUSSEL, Inés. A transmissão cultural assediada: metamorfoses da cultura comum na escola. Cadernos de Pesquisa, São Paulo - Fundação Carlos Chagas, v.39, nº137, p.351-365, maio/ago. 2009.

FRIGOTTO, Gaudêncio; CIAVATTA, Maria. Perspectivas sociais e políticas da formação de nível médio: avanços e entraves nas suas modalidades. Educação e Sociedade, Campinas, v.32, n.116, p.619-638, jul-set. 2011. 
GIMENO SACRISTÁN, J. O Currículo: uma reflexão sobre a prática. Tradução por Ernani F. da Fonseca Rosa. 3.ed. Porto Alegre: ArtMed, 1998, 352p.

GIMENO SACRISTÁN, J.; PÉREZ GÓMEZ, A.I. Compreender e transformar o ensino.Tradução por Ernani F. da Fonseca Rosa. 4.ed. Porto Alegre: ArtMed, 2007. 396p.

GOODSON, Ivor F. O currículo em mudança. Estudos na construção social do currículo. Tradução por Jorge Avila de Lima. Porto: Porto Editora, 2001, 231p.

GOODSON, Ivor F. Currículo: teoria e história. Tradução por Attilio Brunetta. Petrópolis: Editora Vozes, 2012. 141p.

MOREIRA, Antonio Flavio Barbosa. A psicologia...e o resto: o currículo segundo César Coll. Cadernos de Pesquisa, São Paulo - Fundação Carlos Chagas, n.100, p.93107, março/1997.

SAUTU, Ruth; BONIOLO, Paula; DALLE, Pablo; ELBERT, Rodolfo. Manual de metodología: construcción del marco teórico, formulación de los objetivos y la elección de la metodología. Buenos Aires: CLACSO, 2005. 192p.

SAVIANI, Dermeval. Educação: do senso comum à consciência filosófica. São Paulo: Cortez Editora /Autores Associados, 1980, 224p.

SENE, José Eustaquio de. As reformas educacionais após abertura política no Brasil e na Espanha: uma análise crítica do ensino médio e da geografia. 2009, 352p. Tese de Doutorado, Universidade de São Paulo: Faculdade de Filosofia, Letras e Ciências Humanas (FFLCH), Departamento de Geografia, Programa de Pós-Graduação em Geografia Humana. USP, fevereiro de 2009. Disponível em:<http://www.teses.usp.br/teses/disponiveis/8/8136/tde-10032010-111707/ptbr.php>. Acesso em: 10 dez. 2016

SCHNEIDER, Sergio; SCHIMITT, Cláudia Job. O uso do método comparativo nas Ciências Sociais. Cadernos de Sociologia, Porto Alegre, v. 9, p. 49-87, 1998.

\section{Como referenciar este artigo}

GARCIA MONTERO, Maria Fernanda Alves. A filosofia no currículo e na percepção de alunos e professores do ensino médio brasileiro e do bachillerato espanhol: estudo comparativo sobre o papel da filosofia e suas condições de ensino. Revista on-line de Política e Gestão Educacional, Araraquara, v.21, n. 2, p. 449-466, maio-ago. 2017. Disponível em: <http://dx.doi.org/10.22633/rpge.v21.n.2.2017.9945>. ISSN: 15199029.

Submetido em: 09/06/2017

Aprovado em: 26/07/2017 